\title{
ELECTROPHORETIC STUDIES OF THE SERUM PROTEINS IN VIRUS HEPATITIS
}

\author{
By WILLIAM E. RICKETTS AND KENNETH STERLING' \\ (From the Frank Billings Medical Clinic, Department of Medicine, The University of Chicago, \\ Chicago, Ill.)
}

(Received for publication June 20, 1949)

The abnormal electrophoretic patterns of the serum proteins in the acute stage of virus hepatitis were first described by Gray and Barron in 1943 (1) and have since been confirmed by several investigators (2-5). In the last few years there has been considerable interest $(6-13)$ in cases of hepatitis progressing to chronic liver disease, or developing post-necrotic cirrhosis. Except for the study by Martin (4), however, little information has been presented on the serum proteins after the acute stage of the disease.

The present investigation was undertaken to observe the alterations of the serum proteins during the course of virus hepatitis, including its later stages.

\section{METHODS}

Electrophoretic runs were performed with standard apparatus and technique, the experimental details having been given in an earlier report (14). The tests of hepatic function were performed by the usual methods as previously described (14), alkaline phosphatase being reported in Bodansky units. In our experience (15), the thymol turbidity test with buffer $\mathrm{pH} 7.55$ has not infrequently given values of 4 or 5 units in normal individuals.

\section{CASE MATERIAL}

Ten volunteer subjects with normal tests of hepatic function served as controls, the data having been previously reported (14).

Twenty-one clinically typical cases of hepatitis were studied. Histologic verification of parenchymal involvement compatible with virus hepatitis was obtained in 14 cases, the tissue having been secured by one or more Vim Silverman needle biopsies or at laparotomy, and in two cases (E. H. and K. H.) at autopsy. On the basis of history the cases were considered to be infectious hepatitis with exception of two (T. H. and K. H.) regarded as homologous serum hepatitis, having received blood and plasma within 60 to 90 days prior to onset.

For the purposes of study, the material was divided into the following three groups:

\footnotetext{
1 Present address : Department of Medicine, Harvard Medical School, Boston, Mass.
}

Group I-Acute phase, ten patients.

Group II-Course of the disease, with serial electrophoretic studies on five patients over periods of 69 to 396 days.

Group III-Late follow-up studies, with single electrotrophoretic analyses on sera from 11 patients, ten to 36 months after the acute phase.

Serial needle biopsies and repeated tests of hepatic function were performed during the course of observation, as described below.

In addition to bed rest during the acute stage, the medical management included a high protein, high carbohydrate, high caloric diet containing 120 to 150 grams of protein, 350 to 450 grams of carbohydrate, a total of 3,000 to 3,500 calories, supplemented in most instances by 4 to 6 grams of choline chloride daily.

\section{RESULTS}

\section{Group I-Acute phase}

In all of the ten cases studied during the acute phase histologic examination of liver tissue was obtained, in two instances (E. H. and K. H.) at autopsy. Two of the ten cases (T. H. and K. H.) were regarded as homologous serum hepatitis, and the rest as infectious hepatitis.

Typical electrophoretic patterns are illustrated in Figure 1, and the data including tests of hepatic function are given in Table $\mathrm{I}$, the cases being listed in order of increasing severity of the disease as judged by the overall clinical picture.

It will be readily observed that diminution of the albumin fraction occurred in all instances even when not evident by the Howe method. Elevation of the gamma-globulin fraction was usually but not invariably present (seven of the ten cases). G. A., J. E., and S. E. exhibited normal gamma-globulins, while $\mathrm{H}$. S. had elevation of the relative proportion (i.e., per cent) but not the absolute value (i.e., grams per cent) of gammaglobulin. Elevated beta-globulins occurred in seven of the ten cases.

The first five cases (C. G., T. J., G. A., J. E., and S. E.) had mild hepatitis with slight to 
moderately intense jaundice. C. G. showed elevated alpha-2-, beta-, and gamma-globulins, with almost normal thymol turbidity and negative cephalin cholesterol flocculation test. T. J. exhibited elevation of all the globulins, with both thymol turbidity and cephalin cholesterol flocculation tests within normal limits. G. A., J. E. (Figure 3), and S. E. had normal gammaglobulins, the first two with elevated beta-globulins (and positive thymol turbidity and cephalin cholesterol flocculation tests), and the latter with elevated alpha-2-globulin and positive thymol turbidity test.

The last five cases (H. S., T. H., A. E., E. H., and K. H.) had severe acute hepatitis. Four of these were women after the menopause $(H . S$., A. E., E. H., and K. H.) and one (T. H.) was a 72 year old male with diffuse arteriosclerosis and hypertension. Three cases recovered clinically from the hepatitis and had no further symptoms referable to liver disease $(H$. S., T. $H$., and A. E.), and two died of parenchymal liver failure with intense jaundice, edema, ascites, and hemorrhagic phenomena ( $E$. $H$. and K. H.). The electrophoretic albumin values in this group were all below 3 grams per cent. H. S. (Figure 2) had only relative but not absolute increase of the beta- and gamma-globulins, while the others all showed pronounced, relative and absolute gamma-globulin elevations. A. E. (Figure 4) and $\mathrm{K}$. H. had elevated beta- as well as gammaglobulins. A high alpha-1-globulin occurred in T. $H$. The abnormalities of the serum proteins in these five cases of severe virus hepatitis were in general considerably more pronounced than in the five with clinically milder disease.

\section{Group II-Course of the disease}

The five cases with follow-up studies showed evolution of the electrophoretic patterns toward

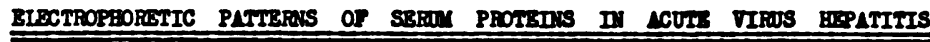

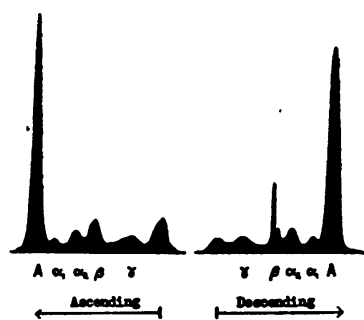

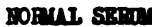

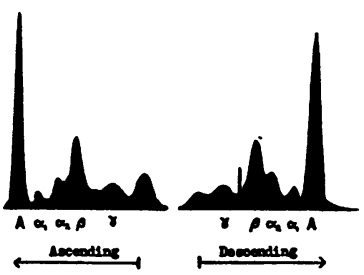

J.B. - Dimint shed albumin, ilevated beta-globulin, noxmal cans-globulin. Iild bepatith of ith intense janndice.

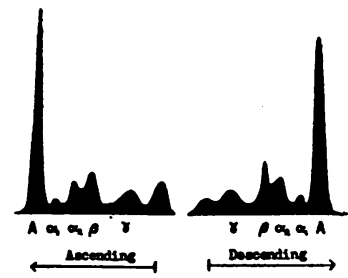

C.G. - Diminisbed albouin, elerated alpha-2-, beta-, and 8 stobuins. ifld bepatitis with slight Jamitice.

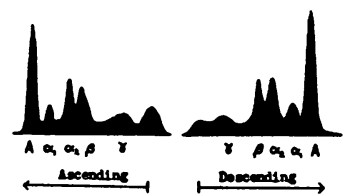

T.J. - Dindinished albumin, al globouin fractions elevated. iild bepatitis with slight jandice.

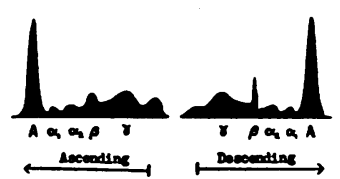

3.B. - Maricedrr abnoral pattern at th dindind shed albudn and elevated gema-elobulin. Fatal infectious bepatitis.

FIG. 1

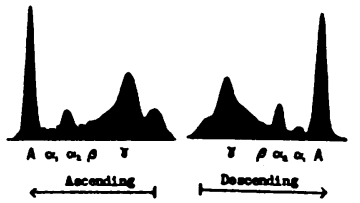

X.B. - Larkedly abeoriel pat tern with diminished albunin and elevated beta- and gamagloberins.

Patai bowlogons serwn hepat1tis.

The albumin peaks are indicated by "A," and the globulins by their respective Greek letter prefixes. The unlabelled peaks are the stationary anomalous boundaries due to gradients of buffer salt. 
TABLE I

ACUTE VIRUS HEPATTPIS

\begin{tabular}{|c|c|c|c|c|c|c|c|c|c|c|c|c|c|c|c|c|c|c|c|c|c|}
\hline \multirow{3}{*}{ Casos } & \multicolumn{11}{|c|}{ Bloctrophorotic data } & \multicolumn{4}{|c|}{ Howo sodium sulfato } & \multicolumn{6}{|c|}{ Tosto of hopat10 sunction } \\
\hline & \multicolumn{5}{|c|}{ por cont } & \multicolumn{5}{|c|}{ exams por cont } & \multirow[b]{2}{*}{$A / G$} & \multirow[b]{2}{*}{$A / G$} & \multicolumn{3}{|c|}{ Exam por cont } & \multicolumn{3}{|c|}{ b111rubin } & \multirow[b]{2}{*}{$\infty$ oph } & \multirow[b]{2}{*}{ then } & \multirow{2}{*}{$\begin{array}{l}\text { alk } \\
\text { phos }\end{array}$} \\
\hline & $\mathrm{Alb}$ & $\alpha_{1}$ & $\alpha_{2}$ & $\beta$ & $\gamma$ & Alb & $\alpha_{1}$ & $\alpha_{2}$ & $\boldsymbol{\beta}$ & $\gamma$ & & & Alb & clob & Tot & 17 & 15 & tot & & & \\
\hline c.G. & 50.2 & 4.6 & 12.9 & 16.5 & 15.8 & 3.54 & 0.32 & 0.91 & 1.16 & 1.21 & 1.01 & 2.77 & 4.50 & 2.54 & 7.04 & 0.9 & 2.1 & 3.1 & nog. & 5.3 & 4.0 \\
\hline T.J. & 35.3 & 10.2 & 19.4 & 19.2 & 15.9 & 2.57 & 0.74 & 1.41 & 1.40 & 1.16 & 0.55 & 2.45 & 5.17 & 2.21 & 7.28 & 0.9 & 1.5 & 1.8 & pog. & 3.6 & 5.4 \\
\hline G.A. & 51.3 & 5.3 & 8.3 & 20.0 & 15.1 & 3.23 & 0.34 & 0.52 & 1.26 & 0.95 & 1.05 & 2.00 & 4.20 & 2.10 & 6.30 & 1.3 & 2.1 & 2.9 & 34 & 7.4 & 8.2 \\
\hline J.E. & 43.5 & 5.4 & 9.7 & 29.4 & 22.0 & 2.88 & 0.36 & 0.64 & 1.95 & 0.79 & 0.77 & 1.46 & 3.90 & 2.68 & 6.62 & 7.5 & 21.8 & 25.6 & 34 & 20 & 12.1 \\
\hline s.5. & 46.3 & 7.1 & 20.4 & 21.4 & 14.8 & 3.03 & 0.46 & 1.34 & 0.75 & 0.97 & 0.86 & 1.37 & 3.79 & 2.76 & 6.55 & 3.0 & 4.7 & 7.0 & 24 & 20.5 & 21.0 \\
\hline B.8. & 44.0 & 7.4 & 10.8 & 19.7 & 18.1 & 2.15 & $\overline{0.36}$ & 0.53 & 0.97 & 0.89 & 0.79 & 1.33 & 2.80 & 2.10 & 4.90 & 5.4 & 7.8 & 9.8 & 34 & 7.5 & 9.5 \\
\hline T.E. & 46.0 & 12.3 & 7.3 & 7.3 & 27.1 & 2.55 & 0.69 & 0.41 & 0.41 & 2.50 & 0.85 & 1.19 & 3.02 & 2.54 & 5.56 & 4.6 & 7.6 & 20.8 & $4 t$ & 220 & 17.5 \\
\hline A.I. & 38.4 & 5.3 & 9.8 & 21.7 & 24.9 & 2.80 & 0.39 & 0.7 & 1.58 & 1.82 & 0.62 & 1.39 & 4.25 & 3.05 & 7.30 & 2.4 & 4.7 & 6.7 & $3+$ & seo & 21.8 \\
\hline I.E. & 43.5 & 4.4 & $\overline{6.8}$ & 24.0 & 31.3 & 2.08 & 0.21 & 0.32 & 0.67 & 1.49 & 0.77 & 0.96 & 2.33 & 2.44 & 4.77 & 4.0 & 5.8 & 10.4 & 44 & 20.0 & 23.0 \\
\hline X.I. & 40.6 & 3.8 & 12.1 & 16.7 & 26.8 & 2.99 & 0.28 & 0.89 & 1.23 & 1.97 & 0.68 & 0.46 & 2.31 & 5.05 & 7.36 & 21.2 & 25.0 & 20.8 & $4 t$ & 120 & 22.9 \\
\hline AVtRACE: & 43.9 & 6.7 & 11.7 & 17.6 & 20.2 & 2.78 & 0.41 & 0.77 & 2.14 & 1.27 & 0.80 & 1.44 & 3.63 & 2.74 & 6.37 & & & & & & \\
\hline $\begin{array}{l}\text { Standard } \\
\text { Dorlation }\end{array}$ & 4.7 & 2.7 & 4.5 & 5.7 & 6.3 & 0.43 & 0.16 & 0.35 & 0.43 & 0.39 & 0.15 & 0.52 & 0.92 & 0.83 & 0.93 & & & & & & \\
\hline
\end{tabular}

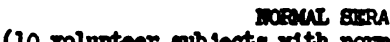

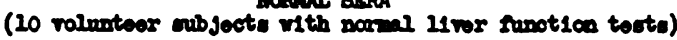

\begin{tabular}{|l|l|l|l|l|l|l|l|l|l|l|l|l|l|l|l|}
\hline AVtrues & 60.3 & 4.0 & 9.7 & 12.8 & 13.2 & 4.23 & 0.28 & 0.68 & 0.89 & 0.93 & 1.52 & 2.31 & 4.89 & 2.12 & 7.02 \\
\hline $\begin{array}{l}\text { Btandard } \\
\text { Doriation }\end{array}$ & 2.8 & 0.8 & 1.5 & 1.2 & 1.7 & 0.29 & 0.06 & 0.10 & 0.08 & 0.13 & 0.18 & 0.34 & 0.30 & 0.24 & 0.30 \\
\hline
\end{tabular}

normal, but differed markedly in both the rate and extent of reversion toward normal. The changes are illustrated in Figures 2-4, and the data including tests of hepatic function are listed in Table II. The initial studies (Day 0$)$ were performed during the acute phase, usually one or two weeks after the onset of the illness.

C. G., a 15 year old male, had mild acute hepatitis with slight jaundice, negative cephalin cholesterol flocculation and almost normal thymol turbidity test. A needle biopsy disclosed histologic changes compatible with virus hepatitis. The initial electrophoretic analysis (Figure 2) revealed somewhat diminished albumin despite normal Howe albumin value, and slightly elevated beta- and gamma-globulins. The jaundice subsided in two weeks; the patient became asymptomatic and remained so. The tests of hepatic function reverted to normal and the electrophoretic pattern on Day 156 was within normal limits. A followup needle biopsy of the liver disclosed normal parenchyma with normal lobular architecture and minimal focal scarring.

J. E., a 35 year old female, had relatively mild acute hepatitis, her general condition remaining quite good despite intense jaundice and pruritus. The total serum bilirubin reached a peak of 18.4 grams per cent; urobilinogen was absent from the 24 hour urine and stool collections for ten days. Microscopic findings on the needle biopsy specimen were compatible with acute virus hepatitis. The initial electrophoretic analysis (Figure 3) revealed diminished albumin and markedly elevated beta-globulin but normal gamma-globulin in the presence of a positive cephalin cholesterol flocculation test and a high thymol turbidity. Over the course of one month the jaundice and all symptoms subsided after which the patient remained asymptomatic. By Day 20 the electrophoretic pattern had changed considerably in the direction of normal and on Day 69, it was within normal limits, as were the tests of hepatic function. Follow-up needle biopsy revealed marked recovery of the parenchyma with no scarring whatever.

H. S., a 72 year old female, had moderately severe acute hepatitis with intense jaundice, the serum bilirubin values attaining levels above $\mathbf{3 0}$ 


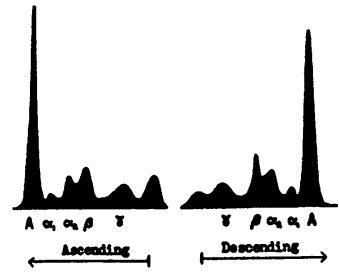

$$
\text { C.6. - Der } 0
$$

Dhringshed alburin, elevated alpha-2-, bota-, and gemmaglobulins.

ifid acute hepatitis with alight jandice.

\section{H.8. - Dar O}

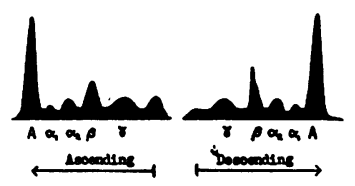

Yarkedly diminishod albouin with only relative increase of beta- and gamn-globulins. Yoderately severe acute bepatitis if th intense jemidie.

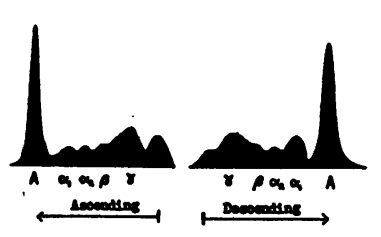

\section{T. I. - Der 0}

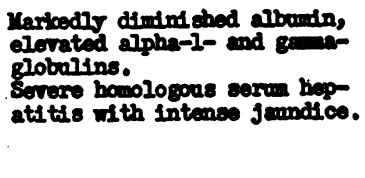

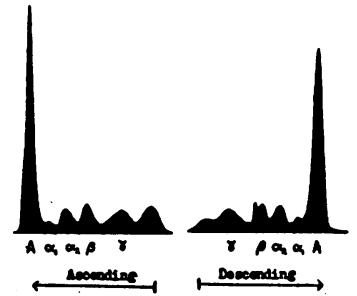

C.0. - Dar 156

Pattern within normal Ifmits. Asyuptomatic. Normal testo of hepatic inotion.
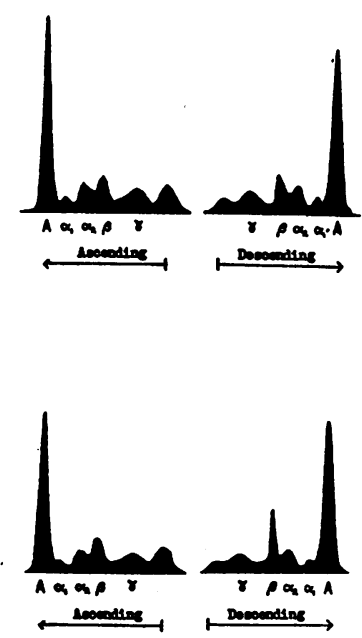

.H.S. - Dar 128

Yarked rise of albuwin, but otill balo noreal. loymptomatic. Teets of hepatic sunction alnost nomal.

T.H. - Der 290

Nboumin still dimint shed, gamma-globritin norial. Balative elevation of Botaglobolin. Layptosatic. Tests of hepatic function allotitis abnormal.

FIG. 2

mg. per cent and the tests of hepatic function revealing marked impairment. Needle biopsy disclosed acute hepatitis with some distortion of the lobular architecture. The initial electrophoretic pattern (Figure 2) was quite abnormal with very low albumin and elevation of the relative (i.e., per cent) but not absolute (i.e., grams per cent) values of the beta- and gamma-globulins. Within five weeks complete clinical recovery occurred with reversion of the tests of hepatic function to almost normal, and the patient remained asymptomatic. Electrophoretic analysis on Day 128 revealed considerable change in the direction of normal with albumin rise of over 1 gram per cent, nevertheless not attaining the normal range.

T. H., a 72 year old male, had severe acute hepatitis with intense jaundice, regarded as homologous serum hepatitis since he had received blood and plasma 90 days previously at the time of a local resection of the colon for carcinoma.
Tests of hepatic function revealed marked impairment and histologic examination of the needle biopsy specimen was compatible with virus hepatitis. The initial electrophoretic study (Figure 2) showed markedly diminished albumin and elevated alpha-1- and gamma-globulins. Complete clinical recovery occurred in approximately six weeks, the tests of hepatic function remaining slightly abnormal. Electrophoretic analysis on Day 290 revealed some change toward normal with decline of the elevated alpha-1- and gammaglobulins, but the pattern was still definitely abnormal with diminution of albumin and relative elevation of beta-globulin.

A. E., a 67 year old female with hypertensive cardio-vascular disease but without history of cardiac failure, developed unusually severe acute hepatitis with intense jaundice, the total serum bilirubin levels exceeding $30 \mathrm{mg}$. per cent. For three weeks urobilinogen was absent from the 24 


\section{COURES OF UTID VITUS BIEPATITIS}

Sere of J.8.

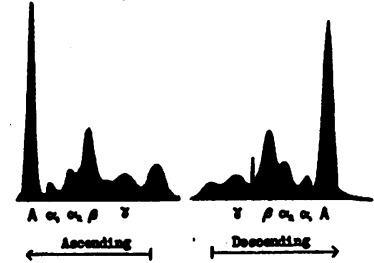

Dero

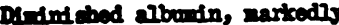
clerated beta-globolin, nornal ginarabein. ald reuts bepatitis with intenes jemantice.

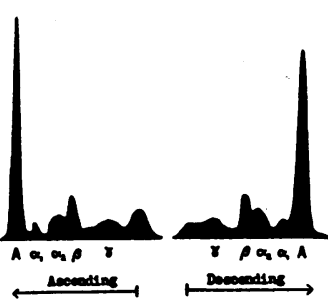

Der 20

Hearly normal pattern. Hinimal jaundice.

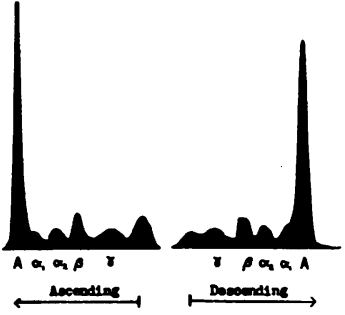

Der 69

Pattern within norial Ifits. Lrymtometile. Pests of hepatic function almost normal.

FIG. 3

hour collections of stools and urine. The other tests of hepatic function disclosed marked impairment. Needle biopsy of the liver four weeks after the onset revealed marked inflammatory infiltration with areas of liver cell necrosis and postnecrotic scarring. The initial electrophoretic pattern (Figure 4) was quite abnormal with diminished albumin and markedly elevated betaand gamma-globulins. After eight weeks of jaundice there was gradual complete clinical re- covery, the patient's cardio-vascular status remaining unchanged throughout. The tests of hepatic function exhibited progressive reversion to almost normal, the thymol turbidity remaining slightly elevated even after a year had elapsed. The electrophoretic pattern on Day 21, by which time considerable clinical improvement had occurred, was still quite abnormal but revealed a rise of the albumin and a decline of the elevated beta- and gamma-globulins. On Day 396, definite

\section{COURSB OF SEVERS VIRUS HISPATIIIS UITH POST-AIECROTIC CIRPADOSIS}

Serre of $\mathbf{A . 5}$.

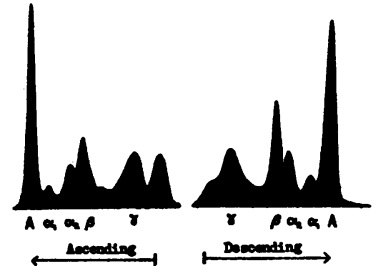

Dero

Markedrs aboormal pattorn with diminished albuin, elorated beter and gana-elobolins. severe sento hepatitis with extreno jemilice.

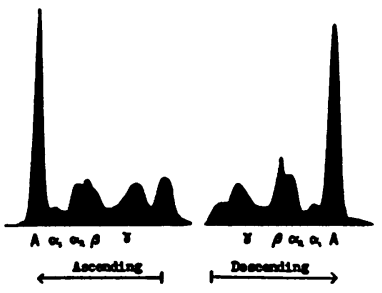

Der 22

Pattorn still quito abooral, but fith sise of allowin, do cline of bete- and gana-globvilins.

Considorable clinical inprovement. Ilinimel jemdice.

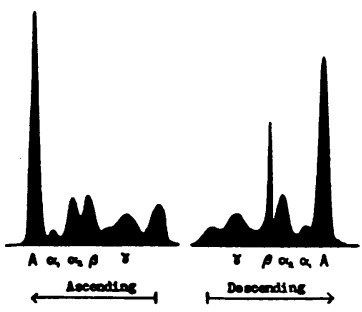

Der 396

Pattern still abnormal with diminished albumin, elevated a)pha-2-, beta-, and ganaglobulins.

isymptomatic. Teats of hepatte Inction almost nornal. Post-necrotic eiriboals instologealif.

FIG. 4 
TABLE II

COUPBi of VIRUS HIPATHYIS

\begin{tabular}{|c|c|c|c|c|c|c|c|c|c|c|c|c|c|c|c|c|c|c|c|c|c|c|}
\hline & \multicolumn{11}{|c|}{ sloctrophorotio date } & \multicolumn{4}{|c|}{ Bove sodium sulfato } & \multicolumn{7}{|c|}{ Tosts of bopatic funotion } \\
\hline & \multicolumn{5}{|c|}{ por cont } & \multicolumn{5}{|c|}{ Exang per oont } & \multirow[b]{2}{*}{$A / C$} & \multirow[b]{2}{*}{$A / G$} & \multicolumn{3}{|c|}{ grams por cont } & \multicolumn{3}{|c|}{ bllirubin } & \multirow[b]{2}{*}{$\infty \mathrm{ph}$} & \multirow{2}{*}{ thom } & \multirow{2}{*}{$\begin{array}{l}\text { elk } \\
\text { phoos }\end{array}$} & \multirow{2}{*}{$\frac{\mathrm{BSP}}{8}$} \\
\hline & Alb & $\alpha_{1}$ & $\alpha_{2}$ & $\beta$ & $\gamma$ & $\mathrm{Alb}$ & $\alpha_{1}$ & $\alpha_{2}$ & $\beta$ & $\gamma$ & & & $A I b$ & Glob/2 & Tot & 1 & $15+$ & 86 & & & & \\
\hline \multicolumn{23}{|c|}{ Sore of c.0. } \\
\hline Das 0 & 50.2 & 4.6 & 12.9 & 16.5 & 15.8 & 3.54 & 0.32 & 0.91 & 1.16 & 1.21 & 1.01 & 1.77 & 4.50 & 2.547 & 7.04 & 0.9 & 2.1 & 3.1 & mg. & 5.3 & 4.0 & --- \\
\hline Das 156 & 58.4 & 3.6 & 10.4 & 22.5 & 15.2 & 3.99 & 0.25 & 0.71 & 0.85 & 1.03 & 1.40 & 2.24 & 4.72 & 2.116 & 6.83 & 0.1 & 0.2 & 0.5 & mo. & 2.9 & $--\infty$ & 2.0 \\
\hline \multicolumn{23}{|c|}{ Bera of J.s. } \\
\hline Das 0 & 43.5 & 3.4 & 9.7 & 29.4 & 22.0 & 2.88 & 0.36 & 0.64 & 1.95 & 0.79 & 0.77 & 1.46 & 3.90 & 2.68 & 6.62 & 7.5 & 21.8 & 15.6 & $3+$ & 720 & 18.5 & $\cdots$ \\
\hline Das 20 & 55.1 & 5.2 & 11.0 & 24.6 & 14.2 & 3.85 & 0.36 & 0.77 & 1.0 & 0.99 & 1.23 & 1.94 & 4.61 & 2.38 & 6.99 & 1.0 & 1.7 & 2.2 & $3+$ & 8.6 & 7.9 & $\ldots$ \\
\hline Das 69 & 60.9 & 5.2 & 8.7 & 12.7 & 12.5 & 4.47 & 0.38 & 0.6 & 0.93 & 0.92 & 1.56 & 2.38 & 5.17 & 2.17 & 7.34 & 0.1 & 0.3 & 0.6 & nog. & 8.0 & 4.6 & 6.5 \\
\hline \multicolumn{23}{|c|}{ Sora of B.8. } \\
\hline Das 0 & 44.0 & 7.4 & 20.8 & 19.7 & 18.1 & 2.15 & 0.36 & 0.53 & 0.97 & 0.89 & 0.79 & 1.33 & 2.80 & 2.101 & 4.90 & 3.4 & 7.8 & 9.8 & $3+$ & 7.5 & 22.8 & $\cdots$ \\
\hline Das 228 & 52.9 & 5.5 & 21.5 & 23.7 & 16.4 & 3.42 & 0.36 & 0.74 & 0.88 & 1.06 & 1.12 & 1.47 & 3.85 & 2.61 & 6.46 & 0.2 & 0.2 & 0.7 & $m 08$. & 5.0 & 5.2 & $\ldots$ \\
\hline \multicolumn{23}{|c|}{ Sora of T.H. } \\
\hline Dar 0 & 46.0 & 12.3 & 7.3 & 7.3 & 27.1 & 2.55 & 0.69 & 0.41 & 0.41 & 1.50 & 0.85 & 1.19 & $3 . \infty$ & 2.54 & 5.56 & 4.6 & $7.6 / 2$ & 20.0 & $4+$ & $>20$ & 15.7 & $\cdots$ \\
\hline Das 290 & 52.3 & 4.3 & 9.9 & 18.0 & 15.5 & 2.75 & 0.23 & 0.52 & 0.95 & 0.81 & 1.10 & 1.92 & 3.46 & 1.80 & 5.26 & 0.2 & 0.3 & 1.2 & mog. & 5.8 & 2.0 & 11.0 \\
\hline \multicolumn{23}{|c|}{ Bora of A.I. } \\
\hline Dar 0 & 38.4 & 5.3 & 9.8 & 21.7 & 24.9 & 2.80 & 0.39 & 0.71 & 1.58 & 1.82 & 0.62 & 1.39 & 4.25 & 3.05 & 7.30 & 2.4 & 4.7 & 6.7 & $3+18$ & $>20$ & 6.4 & $\ldots$ \\
\hline Das 21 & 48.6 & 4.8 & 11.2 & 16.8 & 18.6 & 3.31 & 0.33 & 0.76 & 1.15 & 1.27 & 0.94 & 1.82 & 4.40 & 2.42 & 6.82 & 1.0 & 1.9 & 2.5 & $1+$ & 17.2 & 4.5 & 28.0 \\
\hline Das 396 & 46.8 & 4.4 & 14.8 & 15.4 & 18.6 & 3.40 & 0.32 & 1.07 & 1.12 & 1.35 & 0.88 & 2.01 & 4.85 & 2.41 & 7.26 & 0.1 & 0.2 & 0.4 & nog. & 9.8 & 6.3 & 6.0 \\
\hline
\end{tabular}

residual abnormalities were observed with diminished albumin and elevated alpha-2-, beta-, and gamma-globulins. Follow-up needle biopsy of the liver revealed definite post-necrotic cirrhosis with distortion of the lobular architecture.

\section{Group III-Late follow-up studies}

To assess the late effects of virus hepatitis, single electrophoretic analyses were performed on sera from 11 individuals who had clinically recovered from acute hepatitis during hospital admissions 10 to 36 months previously. In all cases tests of hepatic function had been carried out at intervals. None of the patients were alcoholics or had symptoms referable to the liver or gall bladder prior to the onset of acute hepatitis. Except for C. B., none had recurrent jaundice after the initial episode.

Typical electrophoretic patterns are illustrated in Figure $\mathbf{5}$ and the data including the tests of hepatic function are listed in Table III in order of increasing deviation from normal serum protein composition.

Although most of the residual abnormalities were relatively minor; only three sera (C. B.,
C. J., and W. R.) had patterns well within the normal range. The electrophoretic albumin values (absolute) were slightly diminished in four. (J. G., C. P., M. K., and M. J. S.) of the 11 cases, although this was not reflected in the Howe fractionations. The gamma-globulins were elevated in six cases (G. G., R. W., J. G., C. P., .M. K., and M. J. S.) and the beta-globulins in five (M. S., B. W., G. G., R. W., and M. J. S.).

Summaries of the findings in the 11 cases follow :

C. B., a 24 year old male, had mild infectious hepatitis with intense jaundice while in military service with recurrence of jaundice two months later. He had been asymptomatic during the ensuing 28 months. The electrophoretic pattern was within normal limits. There was definite elevation of the total serum bilirubin, other tests of hepatic function being normal.

C. J., a 29 year old male, had been asymptomatic following recovery from mild acute hepatitis 32 months previously. The electrophoretic data were in the normal range. Tests of hepatic function were normal.

W. R., a 26 year old male, had recovered uneventfully from mild acute hepatitis 34 months previously and remained free of symptoms. The electrophoretic pattern was within normal limits. Tests of hepatic function were normal except for slightly elevated thymol turbidity (6.1 units). Needle biopsy revealed normal liver tissue. 
IATS POLION-UP STUDIES

long after clinical recovery from acute virus bepatitis

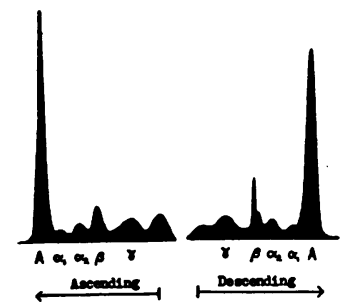

T.R. - Pattern within normal linits.

Asyuptomatic 34 months after mild sento bepatitis. Numost

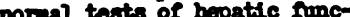
tion. lornel itver histologicallis.

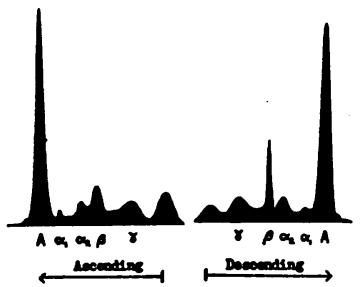

J.Q. - 811ghtls dininiahed albumin, silghtly eletated caman-globurin.

Coymptomatic three years

aftar sovere acuto hepatitis.

Ninot nomal tosts of hepatic

sunotion. 1inimal post-neerotic cearring histologicalls.

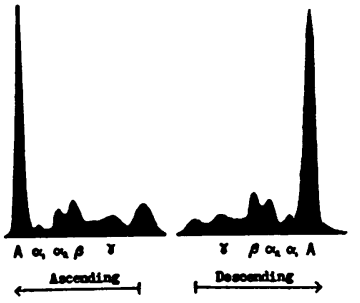

M.8, - Pattern normal except for elerated beta-globulin. isymptomatic lis months aftor severe acute hepatitis. IIormal tests of bepatic function.

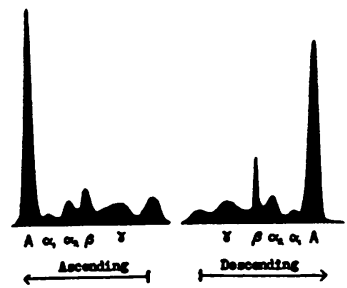

X.X. - SIightly diminishod albounin, elevated gamaglobuitin.

Iojuptonatic Il months after corere acrite hepatitis s. lior-al tests of bepatic fruction. ininal post-necrotic scarring histologicalls.

FIG. 5

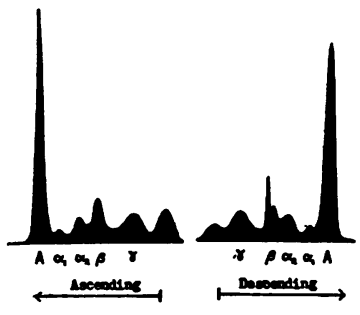

Q.G. - Berated bete- and

gama-globulins. uild acute hepatitis. Horwal tests of hepatic sunction.

TABLE III

LATE FOLIOW-UP STUDIRS

long after clinical recovery from acute virus hepatitis

\begin{tabular}{|c|c|c|c|c|c|c|c|c|c|c|c|c|c|c|c|c|c|c|c|c|c|c|c|}
\hline \multirow{3}{*}{ Cavo } & \multirow{3}{*}{$\begin{array}{l}\text { Wonths } \\
\text { after } \\
\text { acute } \\
\text { stage }\end{array}$} & \multicolumn{11}{|c|}{ Eloctrophorotic data } & \multicolumn{4}{|c|}{ Hove sodium sulfato } & \multicolumn{7}{|c|}{ Toste of hopat10 runction } \\
\hline & & \multicolumn{5}{|c|}{ per cont } & \multicolumn{5}{|c|}{ prans por cont } & \multirow[b]{2}{*}{$A / G$} & \multirow[b]{2}{*}{$A / G$} & \multicolumn{3}{|c|}{ grams per cont } & \multirow{2}{*}{\multicolumn{3}{|c|}{ 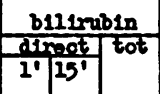 }} & \multirow[b]{2}{*}{$\infty$ coph } & \multirow{2}{*}{ thon } & \multirow{2}{*}{$\begin{array}{l}\text { alk } \\
\text { phoos }\end{array}$} & \multirow{2}{*}{$\underset{\%}{4}$} \\
\hline & & Alb & $\alpha_{1}$ & $\alpha_{2}$ & $\beta$ & $\gamma$ & Alb & $\alpha_{1}$ & $\alpha_{2}$ & $\beta$ & $\gamma$ & & & Ald & Glob: & Tot & & & & & & & \\
\hline C.B. & 28 & 62.6 & 4.2 & 8.5 & 12.8 & 11.9 & 4.26 & 0.28 & 0.58 & 0.87 & 0.81 & 1.67 & 2.56 & 4.89 & 1.91 & 6.80 & 0.2 & 0.5 & 1.5 & nos. & 4.0 & 3.0 & $\cdots$ \\
\hline c.J. & 32 & 62.4 & 3.8 & 6.9 & 12.4 & 14.5 & 4.50 & 0.27 & 0.50 & 0.89 & 1.05 & 1.66 & 2.34 & 5.05 & 2.16 & 7.21 & 0.2 & 0.4 & 1.0 & neg. & 1.6 & 4.8 & 7.5 \\
\hline W.R. & 34 & 59.4 & 4.0 & 7.6 & 13.2 & 15.8 & 4.00 & 0.27 & 0.51 & $|0.89| 1$ & 1.07 & 1.46 & 2.21 & 4.64 & 2.10 & 6.74 & 0.1 & $0.1 \mid$ & -0.5 & nog. & 6.1 & 3.2 & 10.0 \\
\hline M.s. & 14 & 59.8 & 3.6 & 9.3 & 14.7 & 12.6 & 4.58 & 0.28 & $0.71 \mid$ & 1.12 & $|0.96|$ & 1.49 & 1.75 & 4.87 & 2.78 & 7.65 & 0.2 & 0.3 & 0.8 & $n 08$. & 4.0 & 1.8 & 3.0 \\
\hline B.w. & 21 & 57.2 & 4.7 & 8.4 & 15.5 & 14.2 & 4.21 & 0.35 & 0.62 & 1.14 & 1.04 & 1.34 & 2.17 & 5.04 & 2.32 & 7.36 & 0.2 & 0.4 & 0.9 & nog. & 3.9 & 3.3 & 30.0 \\
\hline G.G. & 16 & 54.5 & 3.8 & 9.2 & 15.8 & 16.7 & 4.01 & 0.28 & 0.67 & 1.161 & 1.23 & 1.20 & 1.68 & 4.61 & 2.74 & 7.35 & 0.1 & 0.2 & 0.7 & nos. & 3.2 & 3.4 & 0 \\
\hline R.W. & 12 & 52.2 & 4.1 & 10.5 & {$[14.7]$} & 18.5 & 4.04 & 0.32 & $0.81 \mid$ & 1.14 & 1.43 & 1.09 & 1.50 & 4.64 & $3.10 \mid$ & 7.74 & 0 & 0.1 & 0.5 & nog. & 6.2 & 4.8 & 6.5 \\
\hline J.Q. & 36 & 56.5 & 4.1 & 9.4 & 13.9 & 16.1 & 3.88 & 0.28 & 0.64 & $0.95 \mid 1$ & 1.12 & 1.30 & 2.30 & 4.78 & 2.08 & 6.86 & 0.1 & 0.2 & 1.2 & nes. & 3.6 & 3.5 & 10.0 \\
\hline C.P. & 10 & 54.4 & 5.8 & 9.3 & 12.3 & 18.2 & 3.78 & 0.40 & 0.65 & 0.8612 & 1.26 & 1.29 & 1.70 & 4.38 & 2.57 & 6.95 & 0.2 & 0.3 & 0.6 & 34 & 8.0 & 4.1 & 27.0 \\
\hline M.x. & 24 & 55.6 & 3.9 & 10.6 & 12.6 & 17.3 & 3.80 & 0.27 & 0.73 & $0.86 \mid 1$ & 1.18 & 1.25 & 1.44 & 4.04 & 2.80 & 6.84 & 0 & 0.2 & 0.7 & $n 06$. & 4.8 & 4.0 & 2.5 \\
\hline M.J.8. & 29 & 48.6 & 4.2 & 10.8 & 15.8 & 20.6 & 3.52 & 0.31 & 0.78 & 1.151 & 1.49 & 0.95 & 1.82 & 4.68 & 2.57 & 7.25 & 0 & 0 & 0.2 & $4+$ & 9.0 & 3.2 & 6.5 \\
\hline
\end{tabular}


M. S., a 24 year old male, had severe acute hepatitis with intense jaundice 14 months previously from which he achieved complete clinical recovery. The electrophoretic pattern was normal except for elevated betaglobulin. Tests of hepatic function were normal.

B. W., a 47 year old female, had been asymptomatic following moderately severe acute hepatitis 21 months previously. Electrophoresis disclosed elevation of the beta-globulin fraction. Bromsulfalein test showed 30 per cent retention, the other tests being normal.

G. G., a 50 year old male, had recovered from mild infectious hepatitis 16 months previously and remained asymptomatic thereafter. Electrophoretic analysis revealed elevated beta- and gamma-globulins. All tests of hepatic function were normal.

R. W., a 64 year old male, had recovered uneventfully from mild acute hepatitis 12 months previously. Electrophoresis showed elevation of the beta- and gammaglobulin fractions. The tests of hepatic function were normal except for slightly elevated thymol turbidity (6.2 units).

J. G., a 58 year old male, had been asymptomatic for 36 months following recovery from severe acute hepatitis (with laparotomy biopsy). Electrophoretic analysis revealed diminished albumin and slightly elevated gammaglobulin. The total serum bilirubin was $1.2 \mathrm{mg}$. per cent, other tests of hepatic function being normal. Two consecutive needle biopsies of the liver showed minimal post-necrotic scarring.

C. P., a 55 year old female, had recovered from moderately severe acute hepatitis ten months previously and remained free of symptoms. The electrophoretic findings were diminished albumin and elevated gammaglobulin. Bromsulfalein test showed 27 per cent retention, and the cephalin cholesterol flocculation and thymol turbidity tests were positive.

M. K., a 48 year old male, had been asymptomatic for 14 months after severe acute hepatitis. Electrophoresis revealed diminished albumin and elevated gamma-globulin. Tests of hepatic function were all normal. Needle biopsy of the liver showed minimal post-necrotic scarring.

M. J. S., a 62 year old female, had severe hepatitis (with laparotomy biopsy) 29 months previously with complete clinical recovery. There had been no symptoms referable to the liver since then. The electrophoretic pattern was the most abnormal of the group, with diminished albumin and elevated beta- and gamma-globulins. The cephalin cholesterol flocculation was $4+$ and thymol turbidity was 9.0 units, the highest values in the group, the other tests of hepatic function being normal. Needle biopsy of the liver revealed post-necrotic scarring with disturbed architecture.

\section{DISCUSSION}

Electrophoretic analyses of the serum proteins in virus hepatitis were first described in 1943 by Gray and Barron (1) who reported five cases with diminished albumin in all, elevated gamma- globulin in four, and elevated beta-globulin in two. These observations have been confirmed and extended by subsequent investigations (2-5), including the present study.

The ten cases of acute virus hepatitis studied all exhibited diminished albumin values on electrophoretic analysis, even when not evident by the Howe fractionation. Elevated gamma-globulins occurred in seven of the ten cases, and elevated beta-globulins in the same number, other variations being less frequent.

Comparison of the five clinically mild with the five severe cases of acute hepatitis revealed no strict correlation between clinical severity and extent of deviation from normal serum protein composition. This is well illustrated by the case of $\mathrm{T}$. J. with quite mild clinical manifestations and slight jaundice, yet considerable abnormality of the electrophoretic pattern. On the other hand, the five severe cases all had markedly abnormal patterns, with generally greater deviations from normal than the mild cases.

The changes show similarities to those observed in a previous study of portal cirrhosis (14). The cases of portal cirrhosis with clinical manifestations such as jaundice, edema, or ascites had more pronounced abnormalities, however. In such patients, moreover, beta-globulin increases without marked elevation of gamma-globulin did not occur, in contrast to the virus hepatitis cases G. A. and J. E., with beta-globulin elevations alone. The patterns in acute virus hepatitis also resembled those observed in Weil's disease (16), chronic Brucella hepatitis (17), and infectious mononucleosis (18).

The question has been raised whether these alterations are manifestations of hepatic dysfunction or of the infectious process. Somewhat similar abnormalities have been described in infectious diseases such as syphilis, tuberculosis, typhus, malaria, lymphogranuloma venereum, leprosy, kala-azar and others (19), not believed to involve the liver, or at least not accompanied by clinical hepatic insufficiency. It must, however, be noted that most of the above conditions are characterized by chronic proliferative granulomata or by widespread cellular destruction, hence are not necessarily strictly comparable with virus hepatitis. On the other hand, in lobar pneumonia there are elevations of the alpha-2-globulins 
usually without significant changes in the gammaglobulins $(19,20)$. Although a final answer to the problem cannot be given on the basis of the present evidence, it is suggested that the hepatic involvement in virus hepatitis plays a major role in the disturbances of the serum proteins.

The current interest in the late manifestations of virus hepatitis with prolonged hepatic dysfunction or post-necrotic cirrhosis led to the follow-up studies undertaken. To our knowledge the only previous investigation with serial electrophoretic analyses of virus hepatitis sera has been that of Martin (4) in which the maximum period of observation was 64 days. Martin's data show a number of positive findings on tests of hepatic function at the end of observation, but abnormalities of the electrophoretic patterns in only two of his 11 cases.

The present data, on the contrary, demonstrate the frequent occurrence of residual abnormalities of the serum proteins even after long asymptomatic periods.

Of the five cases followed after the acute phase, two with mild acute hepatitis showed complete reversion to normal serum protein composition. The other three with more severe acute episodes exhibited residual abnormalities of the electrophoretic pattern 128, 290, and 396 days after the initial study even though the patients were asymptomatic and had almost normal tests of hepatic function.

The late follow-up studies on sera from individuals who had clinically recovered from the acute phase of virus hepatitis ten to 36 months previously revealed frequent if usually slight abnormalities of the electrophoretic pattern. Of the 11 examined, only three patterns were considered well within the normal limits. Among the group of sera there were four instances of diminished albumin values, six elevated gammaglobulin fractions, and five elevated beta-globulins. Residual abnormalities in one or more tests of hepatic function were likewise observed. No cases of virus hepatitis with chronic jaundice were encountered.

Post-necrotic scarring was demonstrated on follow-up needle biopsy of the liver in four cases (J. G., M. K., M. J. S., and A. E.). These four patients had normal bromsulfalein tests as well as prompt ( 1 minute) bilirubin values (21). The electrophoretic patterns revealed definite residual abnormalities, relatively minor in J. G. and M. K., and more marked in M. J. S. and A. E.

The occurrence of positive cephalin cholesterol flocculation and thymol turbidity tests in the presence of normal values for gamma-globulin, and conversely the occurrence of abnormalities of the serum proteins without positive flocculation or turbidity tests has been pointed out in the presentation of the data above. These findings, while of interest, are not unexpected in view of the complexity of these reactions. Recent investigations $(3,5,22-26)$ have shed some light on the mechanisms of these tests, such as the evidence for the role of lipo-protein of the beta-globulin fraction in the thymol turbidity test. Nevertheless, many problems of the precise interactions of the proteins remain to be clarified.

\section{SUMMARY}

1. Electrophoretic analyses of the serum proteins in ten cases of acute virus hepatitis revealed diminished albumin values in all, elevated gammaglobulins in seven of the ten, and elevated betaglobulins in the same number.

2. Cases of severe acute hepatitis showed in general more pronounced changes than milder cases, but no strict correlation existed.

3. Serial electrophoretic analyses disclosed reversion of the serum proteins to normal in two cases of acute hepatitis, but persistent abnormalities were observed in three cases despite clinical recovery.

4. Late follow-up studies on sera from 11 individuals who had clinically recovered from acute virus hepatitis ten to 36 months previously revealed residual abnormalities in the electrophoretic patterns of eight of the 11 sera.

\section{ACKNOWLEDGMENTS}

The authors wish to express their gratitude to Dr. E. S. Guzman Barron for making available the electrophoresis apparatus used in this study, and also their indebtedness to Robert S. Levine for his technical assistance.

\section{BIBLIOGRAPHY}

1. Gray, S. J., and Barron, E. S. G., The electrophoretic analyses of the serum proteins in diseases of the liver. J. Clin. Invest., 1943, 22, 191. 
2. Kabat, E. A., Hanger, F. M., Moore, D. H., and Landow, H., The relation of cephalin flocculation and colloidal gold reactions to the serum proteins. J. Clin. Invest., 1943, 22, 563.

3. Moore, D. B., Pierson, P. S., Hanger, F. M., and Moore, D. H., Mechanism of the positive cephalincholesterol flocculation reaction in hepatitis. $\mathrm{J}$. Clin. Invest., 1945, 24, 292.

4. Martin, N. H., The components of the serum proteins in infective hepatitis and in homologous serum jaundice (an electrophoretic study). Brit. J. Exper. Path., 1946, 27, 363.

5. Cohen, P. P., and Thompson, F. L., Mechanism of the thymol turbidity test. J. Lab. \& Clin. Med., 1947, 32, 475.

6. Soffer, L. J., and Paulson, M., Residual hepatic damage in catarrhal jaundice as determined by the bilirubin excretion test. Arch. Int. Med., 1934, 53, 809.

7. Krarup, N. B., and Roholm, K., The development of cirrhosis of the liver after acute hepatitis, elucidated by aspiration biopsy. Acta med. Scandinav., 1941, 108, 306.

8. Dible, J. H., McMichael, J., and Sherlock, S. P. V., Pathology of acute hepatitis; aspiration biopsy studies of epidemic, arsenotherapy and serum jaundice. Lancet, 1943, 2, 402.

9. Altschule, M. D., and Gilligan, D. R., Chronic latent hepatitis following catarrhal jaundice. New England J. Med., 1944, 231, 315.

10. Barker, M. H., Capps, R. B., and Allen, F. W., Chronic hepatitis in the Mediterranean theater; new clinical syndrome. J. A. M. A., 1945, 129, 653.

11. Neefe, J. R., Results of hepatic tests in chronic hepatitis without jaundice; correlation with clinical course and liver biopsy findings. Gastroenterology, 1946, 7, 1.

12. Watson, C. J., and Hoffbauer, F. W., The problem of prolonged hepatitis with particular reference to the cholangiolitic type and to the development of cholangiolitic cirrhosis of the liver. Ann. Int. Med., 1946, 25, 195.
13. Kunkel, H. G., Labby, D. H., and Hoagland, C. L., Chronic liver disease following infectious hepatitis. I. Abnormal convalescence from initial attack. Ann. Int. Med., 1947, 27, 202.

14. Ricketts, W. E., Sterling K., Kirsner, J. B., and Palmer, W. L., Electrophoretic studies of the serum proteins in portal cirrhosis. Gastroenterology, in press.

15. Ricketts, W. E., Unpublished data.

16. Sterling, K., Hepatic function in Weil's disease. Gastroenterology, in press.

17. Sterling, K., and Ricketts, W. E., Unpublished data.

18. Sterling, $\mathrm{K}$., The serum proteins in infectious mononucleosis. Electrophoretic studies. J. Clin. Invest., 1949, 28, 1057.

19. Gutman, A. B., The plasma proteins in disease. Advances in Protein Chemistry, 1948, 4, 155.

20. Blix, G., Quantitative bestimmung von elektrophoretisch getrennten serumglobulinen. Ztschr. f. d. ges. exper. Med., 1939, 105, 595.

21. Ducci, H., and Watson, C. J., The quantitative determination of the serum bilirubin with special reference to the prompt-reacting and the chloroformsoluble types. J. Lab. \& Clin. Med., 1945, 30, 293.

22. Recant, L., Chargaff, E., and Hanger, F. M., Comparison of the cephalin-cholesterol flocculation with the thymol turbidity test. Proc. Soc. Exper. Biol. \& Med., 1945, 60, 245.

23. Hanger, F. M., Abnormalities in the globulin component of serum as demonstrable by the cephalin flocculation test. Tr. A. Am. Physicians, 1947, $60,82$.

24. Kunkel, H. G., and Hoagland, C. L., Mechanism and significance of the thymol turbidity test for liver disease. J. Clin. Invest., 1947, 26, 1060.

25. Maclagan, N. F., and Bunn, D., Flocculation tests with electrophoretically separated serum proteins. Biochem. J., 1947, 41, 580.

26. Wunderly, C., and Wuhrmann, F., The effect of experimental increases in the gamma-globulin and albumin content of sera on the response given by turbidity and flocculation tests. Brit. J. Exper. Path., 1947, 28, 286. 